\title{
Association between brachial-ankle pulse wave velocity and progression of coronary artery calcium: a prospective cohort study
}

\author{
Jong-Young Lee', Seungho Ryu², Sung Ho Lee', Byung Jin Kim', Bum-Soo Kim', Jin-Ho Kang ${ }^{\text {, }}$
} Eun Sun Cheong ${ }^{1}$, Jang-Young Kim³ ${ }^{3}$ Jeong Bae Park ${ }^{4}$ and Ki-Chul Sung ${ }^{1 *}$

\begin{abstract}
Background: Few studies have investigated the association between coronary artery calcium (CAC) progression and arterial stiffness measured by brachial-ankle pulse wave velocity (baPWV). We examined the influence of the severity of baseline baPWV on CAC progression in a large prospective cohort.

Methods: A total of 1600 subjects who voluntarily participated in a comprehensive health-screening program between March 2010 and December 2013 and had baseline baPWV as well as CAC on baseline and serial follow-up computed tomography performed approximately $2.7 \pm 0.5$ years apart were enrolled in the study.

Results: A total of 1124 subjects were included in the analysis (1067 men; mean age, $43.6 \pm 5.1$ years). An increased CAC score was found in 318 subjects (28.3\%) during the follow-up period. Baseline higher baPWV was significantly correlated with CAC progression, especially in subjects with third- and fourth-quartile values (adjusted odds ratio [OR] 2.04; $95 \%$ confidence interval [CI] 1.33-3.15 and OR 2.14; $95 \% \mathrm{Cl}$ 1.34-3.41, respectively) compared with the lowestquartile values ( $P$ for trend $<0.001$ ). A similar effect was observed in diabetic subjects. Among the 835 subjects with a baseline CAC score $=0$, progression to CAC score $>0$ was associated with male sex, diabetes, and higher baPWV. However, among the 289 individuals with a baseline CAC score $>0$, only the presence of CAC itself was predictive of CAC progression.
\end{abstract}

Conclusions: Higher arterial stiffness measured by baPWV could be significantly associated with CAC progression.

Keywords: Arterial stiffness, baPWV, Cardiometabolic risk factors, Cardiovascular disease (CVD), Coronary arterial calcification

\section{Background}

The presence of coronary artery calcium $(\mathrm{CAC})$ is significantly correlated with the risk of coronary heart disease [1] and poor prognosis [2-6]. CAC can be measured using either electron beam computed tomography (CT) or multidetector CT (MDCT) by the Agatston scoring method [7]. In both men and women, CT-measured CAC values are highly sensitive for the presence of $\geq 50 \%$ angiographic stenosis but only moderately specific ( 91

\footnotetext{
*Correspondence: kcmd.sung@samsung.com

1 Division of Cardiology, Department of Medicine, Kangbuk Samsung Hospital, Sungkyunkwan University School of Medicine, \#108, Pyung Dong, Jongro-Ku, Seoul 110-746, Republic of Korea

Full list of author information is available at the end of the article
}

and $49 \%$, respectively) [8]. However, the absence of CAC is highly predictive of the absence of significant coronary artery stenosis and is used to identify individuals at low clinical risk [9].

Although serial measurements of CAC may be useful to assess the activity of the atherosclerotic process or monitor the efficacy of medications used to slow or halt the progression of coronary atherosclerosis, serial CAC studies are of unproven clinical value and are thus not recommended. However, several studies have shown an association between CAC progression and traditional risk factors and increased risk of cardiovascular events [10-12]. 
Arterial stiffness measured by aortic pulse wave velocity (PWV) is a potential predictor of cardiovascular events [13, 14]. Brachial-ankle pulse wave velocity (baPWV), a promising technique used to assess arterial stiffness, is simple, noninvasive, and nonradiating. BaPWV may provide information similar to that derived from central PWV [15] and is independently associated with the presence and severity of coronary artery disease (CAD) [16-18].

Because few studies have investigated the association between baPWV and CAC progression, it is unclear whether baPWV can be used to identify subjects with progressive subclinical CAC. We examined the influence of the severity of baseline baPWV on CAC progression in a prospective cohort.

\section{Methods}

\section{Study subjects}

The Kangbuk Samsung Health Study (KSHS) is a Korean cohort study enrolling all men and women 18 years of age or older who voluntarily undergo comprehensive healthscreening examinations at the Kangbuk Samsung Hospital Healthcare Centers in Seoul and Suwon, South Korea. Our study included all KSHS participants who had undergone cardiac CT scanning and baPWV measurements as part of their chosen comprehensive health-screening examination from March 2010 to December 2013 (Fig. 1). A total of 2650 subjects had CAC on baseline and serial follow-up scans performed approximately $2.7 \pm 0.5$ years apart. Among them, 1,600 subjects underwent baseline baPWV during the same period as the first CT scan. We excluded 97 subjects with a history of definite cardiocerebro-peripheral vascular disease $(\mathrm{n}=52)$, low anklebrachial index $(A B I)(n=1)$, or malignancy $(n=44)$. An additional 379 subjects were excluded because of missing data for the variables included in this study. Finally, total 1124 subjects were included in this analysis (1067 men and 57 women; mean age, $43.6 \pm 5.1$ years). This study was approved by the Institutional Review Board of the Kangbuk Samsung Hospital.

\section{Data collection}

All examinations were conducted at the Kangbuk Samsung Health Screening Center clinics in Seoul and Suwon by trained personnel, following a standardized protocol. A self-administered questionnaire was used to collect information about sociodemographic characteristics, lifestyle factors, medical history, family history, and medication use. Body mass index (BMI) was calculated as weight in kilograms divided by height in meters squared. Trained examiners measured blood pressure in the sitting position at least three times using an automated oscillometric device. Blood was drawn from participants after fasting for $\geq 10 \mathrm{~h}$ and analyzed at the Laboratory Medicine Department at the Kangbuk Samsung Hospital. Diabetes was defined as a self-reported history of diabetes, the use of glucose-lowering medications, and/ or $\mathrm{HbA} 1 \mathrm{c} \geq 6.5 \%$.

BaPWV was recorded in the supine position using a VP-1000 (OMRON, Kyoto, Japan), which measures bilateral brachial and posterior tibial artery pressure waveforms using an oscillometric method with cuffs placed on both arms and ankles. BaPWV was calculated automatically for each arterial segment as the path length divided by the corresponding time interval. A validation study of baPWV measurements in an Asian population reported interobserver and intraobserver correlation coefficients of 0.98 and 0.87 , respectively [19]. The coefficients of variation in our sample for left and right baPWV were 12.3 and $12.6 \%$, respectively. The average baPWV was adopted as the mean of the right and left measurements and used for the analyses.

CT scans were obtained using a Lightspeed VCT XTe64 slice MDCT scanner (GE Healthcare, CA, USA). All scans used the same standard scanning protocol $(2.5 \mathrm{~mm}$ slice thickness, $400 \mathrm{~ms}$ rotation time, $120 \mathrm{kV}$ tube voltage, and 124 mAS ECG-gated dose-modulated tube current $(310 \mathrm{~mA} \times 0.4 \mathrm{~s}))$. CAC was scored following the standard Agatston method [20]. CAC measurements had interobserver and intra-observer intraclass correlation coefficients of 0.99 under this protocol. CAC values were scored by a certified CT technologist and were subsequently blindly overread by a board-certified at least two, radiologist with sufficient experience.

\section{Statistical analysis}

Demographic characteristics and cardiovascular risk factors of the study participants were calculated and stratified by baPWV quartiles. Categorical variables are presented as number (\%) and continuous variables as mean (standard deviation [SD]) or median (interquartile range $[\mathrm{IQR}]$ ) based on the distribution of data. Differences across quartiles were tested using Chi square or analysis of variance (ANOVA) tests. The distribution of continuous variables was evaluated, and right-skewed variables (triglycerides, alanine transaminase [ALT], gamma-glutamyltransferase [GTP], and high-sensitivity C-reactive protein [hsCRP]) were log transformed for the one-way ANOVA. To test for linear trends, we included the median value of each category as a continuous variable in the regression model. To evaluate the association of CAC progression across baPWV quartiles, we used a binomial logistic regression model to estimate odds ratios (ORs) with $95 \%$ confidence intervals (CIs) for $\mathrm{CAC}$ progression. We used three models to progressively adjust for potential confounders. We initially adjusted for 


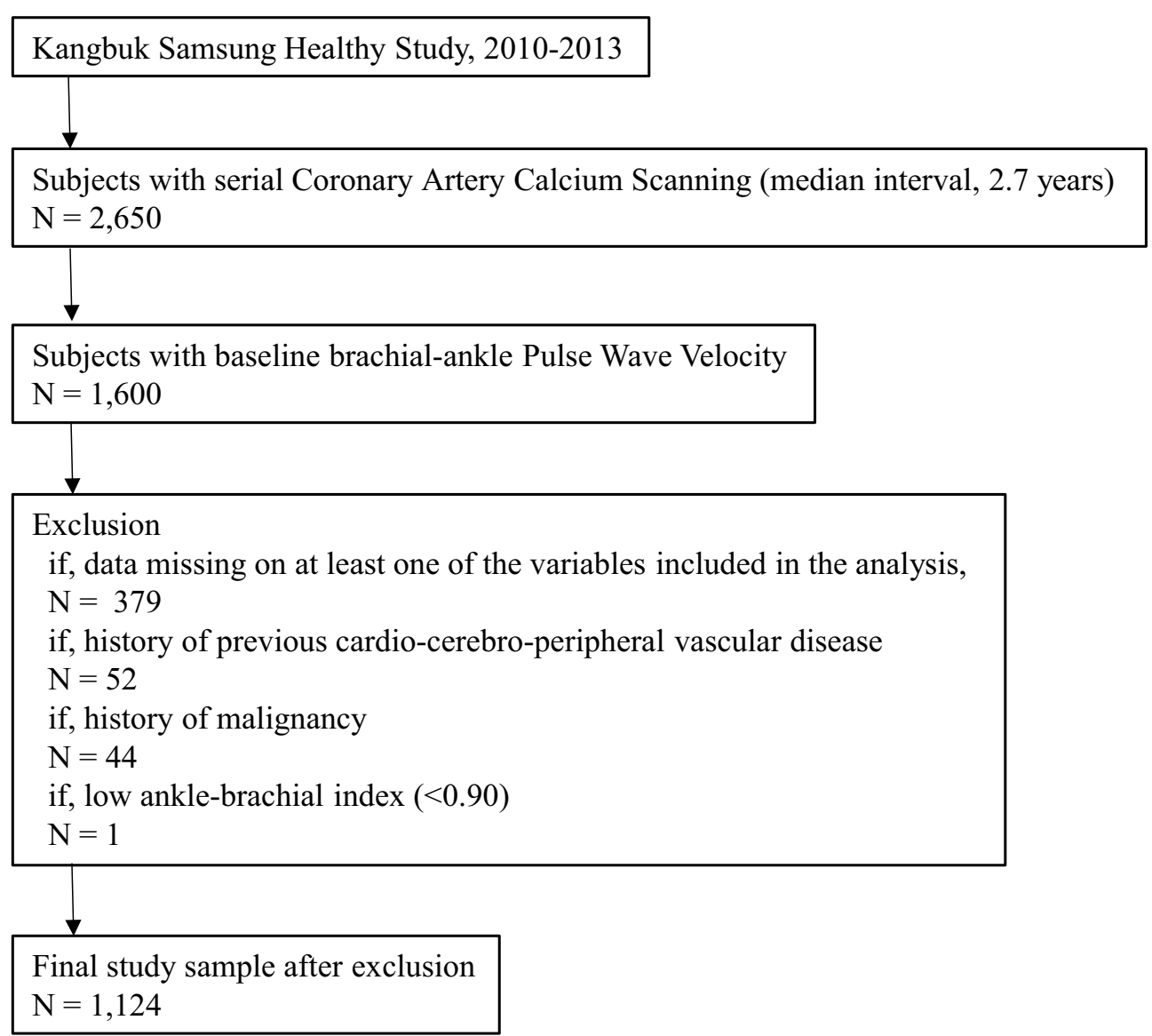

Fig. 1 Study population. This flowchart summarizes the source and study population of this study

age. Model 1 was further adjusted for sex, center, year of screening examination, smoking status, alcohol intake, educational level, BMI, diabetes, hypertension, and high-density lipoprotein (HDL), low-density lipoprotein (LDL), and glucose levels. In model 2, we further adjusted for systolic blood pressure and heart rate. Finally, we analyzed the impact of baPWV and pulse pressure (PP) on $\mathrm{CAC}$ progression by dividing subjects into two groups according to median baPWV and PP values.

A two-sided P value $<0.05$ was considered significant. Statistical analyses were performed using Stata version 12 (Stata Corp. 2011, College Station, TX, USA).

\section{Results}

A total of 1124 subjects had CAC on baseline and followup scans performed approximately $2.7 \pm 0.5$ years apart. Their mean age was 43.6 years, and $94.9 \%$ were men; $31.8 \%$ of subjects were current smokers, $8.2 \%$ had diabetes, and $24.6 \%$ had hypertension. Mean CAC scores were $17.8 \pm 81.8$ at baseline and $29.2 \pm 114.9$ at follow-up. Study participants in the highest baPWV quartiles were more likely to be older, male, or heavy drinkers and have diabetes or hypertension; higher blood pressure, glucose, total cholesterol, triglyceride, ALT, GTP, and CRP; and lower HDL (Table 1).

During the median 2.7-year follow-up period, 318 subjects $(28.3 \%)$ had an increased CAC score at follow-up examination compared with baseline. CAC progression was seen in 76 of 835 subjects $(9.1 \%)$ with baseline $\mathrm{CAC}=0$ but in 242 of 289 subjects $(83.7 \%)$ with baseline $\mathrm{CAC}>0$. Compared with subjects with no change in $\mathrm{CAC}$ values, those with an increase in CAC levels were more likely to be older, male, obese, or heavy drinkers and have diabetes or hypertension; higher BMI, blood pressure, fasting glucose, LDL, ALT, GTP, or CRP; and lower HDL cholesterol (Table 2). Study participants in the highest baPWV quartiles were more likely to have more severe progression of CAC compared with those in the lower baPWV quartiles (Table 3).

In multivariate logistic regression analysis, baseline PWV was significant correlated with CAC progression during follow-up, especially among subjects in the third and fourth quartiles (adjusted OR, 2.04; $95 \% \mathrm{CI}$ 1.33-3.15 and OR, 2.14; $95 \%$ CI 1.34-3.41, respectively) 
Table 1 Baseline characteristics of study participants by brachial-ankle pulse wave velocity quartiles

\begin{tabular}{|c|c|c|c|c|c|}
\hline \multirow[t]{2}{*}{ Characteristics } & \multicolumn{4}{|l|}{ PWV quartiles } & \multirow[t]{2}{*}{ P for trend } \\
\hline & Q1 & Q2 & Q3 & Q4 & \\
\hline PWV (cm/sec) & $977-1256.5$ & $1256.5-1345.5$ & $1345.5-1441.5$ & $1441.5-2397.5$ & $<0.001$ \\
\hline Number & 281 & 281 & 282 & 280 & \\
\hline Age $\left(\right.$ years) ${ }^{a}$ & $42.3(4.5)$ & $43.3(4.3)$ & $43.8(5.2)$ & $45.0(6.0)$ & $<0.001$ \\
\hline Male (\%) & 89.7 & 94.0 & 96.8 & 99.3 & 0.001 \\
\hline BMI $\left(\mathrm{kg} / \mathrm{m}^{2}\right)$ & $25.1(3.3)$ & $24.9(2.8)$ & $25.1(3.2)$ & $25.4(2.9)$ & 0.155 \\
\hline Obesity (\%) & 43.8 & 47.1 & 53.6 & 52.9 & 0.012 \\
\hline Current smoker (\%) & 26.3 & 31.0 & 30.9 & 33.9 & 0.065 \\
\hline Alcohol intake $(\%)^{b}$ & 28.1 & 32.4 & 32.3 & 40.7 & 0.003 \\
\hline High education level $(\%)^{c}$ & 84.2 & 82.3 & 87.7 & 80.8 & 0.655 \\
\hline Diabetes (\%) & 5.0 & 6.4 & 9.6 & 16.1 & $<0.001$ \\
\hline Hypertension (\%) & 10.3 & 23.8 & 26.2 & 42.9 & $<0.001$ \\
\hline Systolic BP $(\mathrm{mmHg})^{\text {a }}$ & $113.9(10.8)$ & $118.7(11.5)$ & $119.3(11.2)$ & $126.5(11.5)$ & $<0.001$ \\
\hline Diastolic BP $(\mathrm{mmHg})^{a}$ & $72.6(8.1)$ & $76.0(8.8)$ & $76.5(8.0)$ & $81.5(9.0)$ & $<0.001$ \\
\hline Glucose $(\mathrm{mg} / \mathrm{dL})^{\mathrm{a}}$ & $94.4(11.1)$ & $98.1(18.3)$ & $99.2(18.1)$ & $105.3(23.6)$ & $<0.001$ \\
\hline Total cholesterol (mg/dL) & $203.5(37.4)$ & $212.0(35.5)$ & $213.6(39.5)$ & $210.8(37.5)$ & 0.020 \\
\hline $\mathrm{LDL}-\mathrm{C}(\mathrm{mg} / \mathrm{dL})^{\mathrm{a}}$ & $126.4(34.1)$ & $133.5(32.3)$ & $134.6(34.6)$ & $130.1(33.8)$ & 0.174 \\
\hline $\mathrm{HDL}-\mathrm{C}(\mathrm{mg} / \mathrm{dL})^{\mathrm{a}}$ & $53.2(13.8)$ & $50.5(10.7)$ & $49.7(11.4)$ & $51.0(12.0)$ & 0.022 \\
\hline Triglycerides $(\mathrm{mg} / \mathrm{dL})^{d}$ & $114(80-156)$ & $138(98-192)$ & $139(99-200)$ & $163(114-227.5)$ & $<0.001$ \\
\hline $\operatorname{ALT}(U / I)^{d}$ & $22(16-31)$ & $24(18-35)$ & $27(20-41)$ & $28(20-42)$ & $<0.001$ \\
\hline $\operatorname{GTP}(U / I)^{d}$ & $29(19-43)$ & $35(24-54)$ & $40(26-58)$ & $41(28.5-68)$ & $<0.001$ \\
\hline C-reactive protein $(\mathrm{mg} / \mathrm{L})^{d}$ & $0.05(0.03-0.12)$ & $0.06(0.04-0.11)$ & $0.07(0.04-0.11)$ & $0.07(0.04-0.14)$ & 0.005 \\
\hline
\end{tabular}

Data are a means (standard deviation), ${ }^{d}$ medians (interquartile range), or percentages

SI unit conversion (multiply the conversion factors to obtain the SI unit): glucose, 0.0555 (mmol/L); Total cholesterol, 0.0259 (mmol/L); LDL-C, 0.0259 (mmol/L); HDL-C, 0.0259 ( $\mathrm{mmol} / \mathrm{L})$; Triglyceride, $0.0113(\mathrm{mmol} / \mathrm{L}) ;$ C-reactive protein, $10(\mathrm{mg} / \mathrm{L})$

ALT alanine aminotransferase, GTP glutamyl transpeptidase, BMI body mass index, BP blood pressure, $H D L-C$ high-density lipoprotein-cholesterol, ${ }^{\mathrm{b}} \geq 20 \mathrm{~g} /$ day;

c $\geq$ College graduate

compared with those in the lowest quartile ( $\mathrm{P}$ for trend $<0.001$ ) (Table 4). In diabetic patients, these associations remained significant for subjects in the third and fourth quartiles (adjusted OR, 3.50; $95 \%$ CI 1.80-5.20 and OR 3.85 ; $95 \%$ CI 1.88-5.82, respectively). Another analyses using SQRT method to determine CAC progression and baPWV also showed significant correlation between them (Additional file 1: Tables 1, 2). Using a cutoff point of 10 in CAC change, the progression of CAC was still significantly associated with baseline baPWV (Additional file 1: Table 3).

Among study subjects with baseline $\mathrm{CAC}=0$, higher baPWV could better predict the likelihood of CAC progression compared with lower baPWV quartile values (Table 5), although baseline PP could not predict CAC progression (higher PP group, adjusted hazard ratio [HR], 0.92; $95 \%$ CI 0.63-1.27, compared with lower half of PP). After analyzing the interaction between PP and PWV, PP was still not a significant predictor or CAC progression. Only higher PWV (>50\%), regardless of $\mathrm{PP}$, was significantly associated with $\mathrm{CAC}$ progression (Table 6).
In multivariate analysis, progression to $\mathrm{CAC}>0$ among 835 subjects with $C A C=0$ was associated with male sex (OR 3.10; 95 \% CI 2.25-3.95; $\mathrm{P}<0.001$ ), diabetes (OR $1.90 ; 95 \%$ CI 1.05-2.85; $\mathrm{P}=0.004$ ), and higher PWV (OR $1.85 ; 95 \%$ CI $1.20-2.45 ; \mathrm{P}=0.001)$. However, among the 289 individuals with baseline $\mathrm{CAC}>0$, only the presence of CAC itself (OR, 14.85; $95 \%$ CI 12.10-17.25; P < 0.001) rather than other $\mathrm{CAD}$ risk factors was predictive of CAC progression.

\section{Discussion}

Our study clearly demonstrates that arterial stiffness, measured by baPWV, can predict progression of CAC in Korean adults and suggests that noninvasive, nonradiating, and readily available baPWV could be a better surrogate marker of CAC progression than PP. The findings of our study are consistent with those of other studies showing a significant association between several surrogate markers of arterial stiffness (measured using various parameters) and CAC [14, 16, 17, 21, 22].

Several clinical risk factors including microalbuminuria or statin use are related to CAC incidence and 
Table 2 Baseline characteristics of study participants by Coronary Calcium Score change in serial examination

\begin{tabular}{|c|c|c|c|}
\hline \multirow[t]{2}{*}{ Characteristics } & \multicolumn{2}{|l|}{ CAC change } & \multirow[t]{2}{*}{ P for trend } \\
\hline & $C A C$ change $=0$ & CAC change $>0$ & \\
\hline Number & 806 & 318 & \\
\hline Age (years) ${ }^{a}$ & $42.9(5.0)$ & $45.3(5.2)$ & $<0.001$ \\
\hline Male (\%) & 93.1 & 99.7 & $<0.001$ \\
\hline BMI $\left(\mathrm{kg} / \mathrm{m}^{2}\right)$ & $24.9(3.0)$ & $25.8(2.9)$ & $<0.001$ \\
\hline Obesity (\%) & 45.4 & 59.1 & $<0.001$ \\
\hline Current smoker (\%) & 32.5 & 30.9 & 0.605 \\
\hline Alcohol intake $(\%)^{b}$ & 32.3 & 38.7 & 0.018 \\
\hline $\begin{array}{l}\text { High education level } \\
(\%)^{c}\end{array}$ & 82.9 & 86.2 & 0.188 \\
\hline Diabetes (\%) & 7.1 & 14.5 & $<0.001$ \\
\hline Hypertension (\%) & 21.8 & 35.9 & $<0.001$ \\
\hline Systolic BP $(\mathrm{mmHg})^{\mathrm{a}}$ & $118.9(12.3)$ & $121.3(11.4)$ & 0.003 \\
\hline Diastolic BP $(\mathrm{mmHg})^{\mathrm{a}}$ & $76.1(9.1)$ & $77.9(8.7)$ & 0.002 \\
\hline Glucose $(\mathrm{mg} / \mathrm{dL})^{\mathrm{a}}$ & $97.6(16.4)$ & $103.4(23.2)$ & $<0.001$ \\
\hline $\begin{array}{l}\text { Total cholesterol } \\
(\mathrm{mg} / \mathrm{dL})^{\mathrm{a}}\end{array}$ & $206.4(37.1)$ & $219.1(37.6)$ & $<0.001$ \\
\hline $\mathrm{LDL}-\mathrm{C}(\mathrm{mg} / \mathrm{dL})^{\mathrm{a}}$ & $127.9(33.0)$ & $139.5(34.5)$ & $<0.001$ \\
\hline $\mathrm{HDL}-\mathrm{C}(\mathrm{mg} / \mathrm{dL})^{\mathrm{a}}$ & $51.7(12.4)$ & $49.6(11.0)$ & $<0.001$ \\
\hline $\begin{array}{l}\text { Triglycerides } \\
(\mathrm{mg} / \mathrm{dL})^{\mathrm{d}}\end{array}$ & $130(90-191)$ & $153(113-215)$ & $<0.010$ \\
\hline $\operatorname{ALT}(U / I)^{d}$ & $25(18-37)$ & $28(20-40)$ & $<0.001$ \\
\hline $\operatorname{GTP}(U / I)^{d}$ & $34(22-54)$ & $40(27-65)$ & $<0.001$ \\
\hline $\begin{array}{l}\text { C-reactive protein } \\
(\mathrm{mg} / \mathrm{L})^{\mathrm{d}}\end{array}$ & $0.06(0.03-0.11)$ & $0.07(0.04-0.13)$ & 0.022 \\
\hline
\end{tabular}

Data are ${ }^{\text {a }}$ means (standard deviation), ${ }^{d}$ medians (interquartile range), or percentages

SI unit conversion (multiply the conversion factors to obtain the SI unit): glucose $0.0555(\mathrm{mmol} / \mathrm{L})$; Total cholesterol, $0.0259(\mathrm{mmol} / \mathrm{L}) ; \mathrm{LDL}-\mathrm{C}, 0.0259(\mathrm{mmol} / \mathrm{L})$; HDL-C, 0.0259 (mmol/L); Triglyceride, $0.0113(\mathrm{mmol} / \mathrm{L})$; C-reactive protein, 10 $(\mathrm{mg} / \mathrm{L})$

$A L T$ alanine aminotransferase, GTP glutamyl transpeptidase, $B M I$ body mass index, $B P$ blood pressure, $H D L-C$ high-density lipoprotein-cholesterol; ${ }^{b} \geq 20 \mathrm{~g} /$ day; ${ }^{c} \geq$ College graduate

progression, especially in patients with diabetes mellitus [23-26]. CAC nearly inevitably progress, with limited influence of traditional risk factors, so prediction or calculation of progression of CAC might be important [25,
27]. Because CAC scanning using MDCT is a test commonly used in clinical practice as a single examination rather than serial examinations, performance of multiple $\mathrm{CAC}$ tests in the same setting might be impracticable and hazardous owing to radiation exposure. Although serial measurements of CAC might be meaningful, no intervention, including statin therapy [28], has been shown to slow CAC progression, and serial measurements of $\mathrm{CAC}$ are of unproven clinical value. On the other hand, baPWV is a relatively simple, noninvasive, nonradiating, and readily available combined measure of central and peripheral arterial stiffness. Unlike carotid-femoral pulse wave velocity, which is a measure of central arterial stiffness, baPWV is a combined measure of central and peripheral arterial stiffness. BaPWV may provide information similar to that derived from central PWV [15] and is independently associated with the presence and severity of CAC $[16,17,29]$. Our study shows a significant correlation between baPWV and CAC progression in apparently healthy subjects. From a clinical perspective, this convenient, nonradiating, and easily available tool may help identify CAC progression, irrespective of CAC presence.

Several plausible mechanisms may be responsible for the association between baPWV and coronary atherosclerosis as expressed by CAC. First, some common risk factors possibly contribute to arterial stiffness and atherosclerosis, and this is more likely in the peripheral arteries. ABI is also associated with the incidence and severity of coronary atherosclerosis [30]. Secondly, given that the aorta forms a large portion of the arterial tree over which baPWV is measured, $58 \%$ of the variation in baPWV can be explained by aortic PWV [15]. Thus, baPWV is not only a marker of peripheral arterial stiffness but also an indirect marker of central arterial stiffness. Thirdly, arterial stiffness could increase the mechanical shear stress on the arterial wall side and cardiac afterload. This can trigger the initial pathophysiologic cascade, which leads to atherosclerotic changes and cardiac remodeling.

Diabetes mellitus is associated with an increased risk of arterial stiffness and atherosclerotic cardiovascular

Table 3 Degree of change in Coronary Calcium Score according to brachial-ankle pulse wave velocity quartiles

\begin{tabular}{|c|c|c|c|c|c|}
\hline \multirow[t]{2}{*}{ Characteristics } & \multicolumn{4}{|l|}{ PWV quartiles } & \multirow[t]{2}{*}{ P for trend } \\
\hline & Q1 (N = 281) & $\mathrm{Q} 2(\mathrm{~N}=281)$ & Q3 (N = 282) & $\mathrm{Q} 4(\mathrm{~N}=280)$ & \\
\hline \multicolumn{5}{|c|}{ Amount of interval change } & \multirow[t]{5}{*}{$<0.001$} \\
\hline No interval change & 232 & 219 & 184 & 171 & \\
\hline $1-9$ & 117 & 19 & 33 & 31 & \\
\hline $10-99$ & 29 & 38 & 59 & 60 & \\
\hline$\geq 100$ & 3 & 5 & 6 & 18 & \\
\hline
\end{tabular}


Table 4 The risk of progression of Coronary Calcium Score according to baseline brachial-ankle pulse wave velocity quartiles odds ratio $(95 \% \mathrm{Cl})$ of CAC change $>0$ by PWV quartiles

\begin{tabular}{|c|c|c|c|c|c|}
\hline & \multirow[t]{2}{*}{ Number } & \multirow[t]{2}{*}{ Cases } & \multirow[t]{2}{*}{ Age-adjusted $\mathrm{OR}^{\mathrm{a}}(95 \% \mathrm{Cl})$} & \multicolumn{2}{|c|}{$\begin{array}{l}\text { Multivariate-adjusted } \mathrm{OR}^{\mathrm{a}} \\
(95 \% \mathrm{Cl})\end{array}$} \\
\hline & & & & Model 1 & Model 2 \\
\hline \multicolumn{6}{|l|}{ Total } \\
\hline Q1 & 281 & 47 & 1.00 (reference) & 1.00 (reference) & 1.00 (reference) \\
\hline Q2 & 281 & 63 & $1.29(0.84-1.98)$ & $1.12(0.72-1.75)$ & $1.16(0.74-1.82)$ \\
\hline Q3 & 282 & 99 & $2.31(1.54-3.47)$ & $1.95(1.27-2.99)$ & $2.04(1.33-3.15)$ \\
\hline Q4 & 280 & 109 & $2.34(1.55-3.52)$ & $1.90(1.22-2.95)$ & $2.14(1.34-3.41)$ \\
\hline P for trend & & & $<0.001$ & 0.001 & $<0.001$ \\
\hline
\end{tabular}

OR odds ratio, $\mathrm{Cl}$ confidence interval

a Estimated from logistic regression. Multivariable model 1 was adjusted for age, sex, center, year of screening exam, smoking status, alcohol intake, educational level, BMI, diabetes, hypertension, HDL, LDL and glucose; model 2: model 1 plus adjustment for sbp and heart rate

Table 5 Risk of progression of Coronary Calcium Score according to baseline brachial-ankle pulse wave velocity quartiles odds ratio $(95 \% \mathrm{Cl})$ of $\mathrm{CAC}$ change $>0$ by PWV quartiles among subjects with baseline $\mathrm{CAC}=0$

\begin{tabular}{|c|c|c|c|c|c|}
\hline & \multirow[t]{2}{*}{ Number } & \multirow[t]{2}{*}{ Cases } & \multirow[t]{2}{*}{$\begin{array}{l}\text { Age-sex-adjusted } \\
\text { OR }^{\mathrm{a}}(95 \% \mathrm{Cl})\end{array}$} & \multicolumn{2}{|c|}{$\begin{array}{l}\text { Multivariate-adjusted } \mathrm{OR}^{\mathrm{a}} \\
(95 \% \mathrm{Cl})\end{array}$} \\
\hline & & & & Model 1 & Model 2 \\
\hline \multicolumn{6}{|l|}{ Total } \\
\hline Q1 & 236 & 8 & 1.00 (reference) & 1.00 (reference) & 1.00 (reference) \\
\hline Q2 & 219 & 17 & $1.22(0.93-5.27)$ & $2.28(0.94-5.51)$ & $1.26(0.93-5.50)$ \\
\hline Q3 & 202 & 30 & $4.38(1.95-9.83)$ & $4.21(1.83-9.68)$ & $1.15(1.79-9.61)$ \\
\hline Q4 & 178 & 21 & $3.05(1.31-7.12)$ & $3.16(1.29-7.70)$ & $3.04(1.20-7.73)$ \\
\hline $\mathrm{P}$ for trend & & & 0.003 & 0.004 & 0.006 \\
\hline
\end{tabular}

OR odds ratio, $\mathrm{Cl}$ confidence interval

a Estimated from logistic regression. Multivariable model 1 was adjusted for age, sex, center, year of screening exam, smoking status, alcohol intake, educational level, BMI, diabetes, hypertension, HDL, LDL and glucose; model 2: model 1 plus adjustment for sbp and heart rate

Table 6 Risk of progression of Coronary Calcium Score according to pulse pressure and brachial-ankle pulse wave velocity odds ratio ${ }^{\mathrm{a}}(95 \% \mathrm{Cl})$ of CAC change $>0$ by PWV50 \% and pulse pressure $50 \%$

\begin{tabular}{|c|c|c|c|c|c|}
\hline & \multirow[t]{2}{*}{ Number } & \multirow[t]{2}{*}{ Cases } & \multirow{2}{*}{$\begin{array}{l}\text { Age and sex-adjusted } \\
\text { OR }^{\mathrm{a}}(95 \% \mathrm{Cl})\end{array}$} & \multicolumn{2}{|c|}{ Multivariate-adjusted $\mathrm{OR}^{\mathrm{a}}(95 \% \mathrm{Cl})$} \\
\hline & & & & Model 1 & Model 2 \\
\hline \multicolumn{6}{|l|}{ Pulse pressure } \\
\hline Pulse pressure $<50 \%$ & 574 & 159 & 1.00 (reference) & 1.00 (reference) & 1.00 (reference) \\
\hline Pulse pressure $\geq 50 \%$ & 550 & 159 & $1.01(0.77-1.32)$ & $0.91(0.68-1.21)$ & $0.90(0.63-1.28)$ \\
\hline \multicolumn{6}{|l|}{ Pulse Pressure and Pulse Wave Velocity } \\
\hline PWV $<50 \%$ and pulse pressure $<50 \%$ & 322 & 66 & 1.00 (reference) & 1.00 (reference) & 1.00 (reference) \\
\hline PWV $<50 \%$ and pulse pressure $\geq 50 \%$ & 240 & 44 & $0.90(0.58-1.39)$ & $0.85(0.54-1.33)$ & $0.90(0.55-1.46)$ \\
\hline PWV $\geq 50 \%$ and pulse pressure $<50 \%$ & 252 & 93 & $2.01(1.37-2.95)$ & $1.82(1.22-2.72)$ & $1.88(1.26-2.82)$ \\
\hline PWV $\geq 50 \%$ and pulse pressure $\geq 50 \%$ & 310 & 115 & $1.88(1.30-2.72)$ & $1.57(1.06-2.32)$ & $1.75(1.09-2.80)$ \\
\hline P for trend & & & $<0.001$ & 0.002 & $<0.001$ \\
\hline
\end{tabular}

$O R$ odds ratio, $\mathrm{Cl}$ confidence interval

a Estimated from logistic regression. Multivariable model 1 was adjusted for age, sex, center, year of screening exam, smoking status, alcohol intake, educational level, $\mathrm{BMI}$, diabetes, hypertension, $\mathrm{HDL}, \mathrm{LDL}$ and glucose; model 2: model 1 plus adjustment for sbp and heart rate 
disease. [31] Vascular calcification, including coronary artery calcification, significantly improved the prediction of outcome compared with the consideration of traditional risk factors, [32, 33] and baPWV improved the ability to identify diabetic individuals at high risk of future cardiovascular events. [34] The combined assessment of CAC and baPWV also could more effectively predict cardiac events than the CAC score alone [35]. Therefore, to predict future events, baPWV might have the potential for wide clinical applications, especially in diabetic patients.

Our study showed that PP, a surrogate marker of arterial stiffness, could not predict CAC progression, unlike baPWV. Generally, increases in PP result from factors that increase and/or decrease systolic and diastolic pressure, respectively. Changes in PP are mostly related to changes in systolic blood pressure, particularly among the elderly, and are usually the result of stiffness in the large arteries as well as an early pulse wave reflection. Although increases in peripheral vascular resistance appear to be a relatively more important component of hypertension in younger patients (younger than 50 years), the role of peripheral vascular resistance in hypertension diminishes progressively with age [36, 37]. Given the known effects of aging on vessel stiffness, increases in PP in older patients result from aortic stiffening, whereas increases in younger patients are more likely to result from increases in stroke volume. Subjects in our cohort had an average age of 43.6 years, which means that higher PP is not likely related to higher arterial stiffness and as a result is not associated with CAC progression.

In our study, during the follow-up period of $2.7 \pm 0.5$ years, approximately $9.1 \%$ of subjects $(76 / 835)$ with $\mathrm{CAC}=0$ at baseline had increases in CAC, whereas CAC progression was observed in $83.7 \%$ of subjects $(242 / 289)$ with a baseline CAC $>0$. This conversion rate is very similar to that reported in a previous study [38]. In that study, 106 of 422 subjects $(25.1 \%)$ with no baseline CAC had a positive CAC score during the follow-up period. Conversion from a CAC score of 0 to $>0$ occurred in $2(0.5 \%), 5$ (1.2\%), 24 (5.7\%), 26 (6.2\%), and 49 (11.6\%) subjects after 1, 2, 3, 4, and 5 years of follow up, respectively [38]. Our study also showed that the presence of diabetes, male sex, and higher baPWV were associated with $\mathrm{CAC}$ progression in subjects with baseline $C A C=0$ whereas in subjects with baseline CAC $>0$, only the presence of CAC could predict CAC progression. So far, no clinical factor seems to mandate repeat CAC scanning, but baPWV is able to help predict CAC progression.

\section{Limitations}

The chief limitation of our study was a lack of data regarding how patients with normal CAC values were treated by their physicians. The treatment of risk factors such as hypertension, diabetes, or dyslipidemia was left to the discretion of the physicians and subjects, which could have resulted in significant treatment bias. Thus, it is difficult to determine the magnitude of any confounding effects of treatment for risk factors that may have altered the natural course of CAC progression. Additional unmeasured confounders that can modify calcification processes, such as fetuin A, novel inflammatory markers, and additional risk factors (e.g., renal failure, thyroid status, or family history), may mediate this accelerated risk. This study did not evaluate such markers but instead limited its evaluation to the association between baPWV and CAC progression. Secondly, the study design was cross-sectional, which might preclude casual correlation. Thirdly, arterial stiffness was measured using baPWV, for which there is a relative lack of scientific evidence compared with carotid-femoral PWV, the gold standard of arterial stiffness measurement. However, previous studies have shown a high correlation between baPWV and aortic PWV [39]. Currently, baPWV is widely used in Asia, and evidence of its value is growing with time. Fourthly, our study comprised Korean adults voluntarily attending a health-screening program and was primarily performed in men, a small proportion of whom had diabetes. Fifthly, a CAC score between 0 and 10 is likely to represent noise. Although the reproducibility of CAC scores is high, the reproducibility of scores between 0 and 9 is an issue. As compared to those who scored 10 or greater, variation was very high among subjects who scored between 0 and 9, which might have had a significant impact on our results. Finally, our follow-up period was relatively short, without evaluation of clinical outcomes, which gives our findings limited generalizability.

\section{Conclusions}

Higher arterial stiffness measured by baPWV could be significantly associated with CAC progression.

\section{Additional file}

Additional file 1: Table 1. The Risk of Progression of Coronary Calcium Score According to Baseline Brachial-Ankle Pulse Wave Velocity: Odds Ratio (95\% Confidence Interval) of Difference $\left[\sqrt{C A C}_{\text {(follow-up) }}-\right.$ $\left.\sqrt{ } \mathrm{CAC}_{\text {(baseline) }}\right]>2.5$ by Pulse Wave Velocity quartiles-The SQRT Analysis. Table 2. The Risk of Progression of Coronary Calcium Score According to Pulse Pressure and Brachial-ankle Pulse Wave Velocity: Odds ratio (95\% Confidence Interval) of Difference $\left[\sqrt{ } C C_{(\text {follow-up) }}-{\sqrt{ } C A C_{(\text {baseline) }}}\right]>2.5$ by Pulse Wave Velocity $50 \%$ and pulse pressure $50 \%$-The SQRT Analysis. Table 3. The Risk of Progression of Coronary Calcium Score According to Baseline Brachial-Ankle Pulse Wave Velocity: Odds ratio (95 \% Confidence Interval) of Coronary Calcium Score Change change $>=10$ by Pulse Wave Velocity Quartiles. 


\section{Abbreviations}

ABI: ankle-brachial index; ALT: alanine transaminase; baPWV: brachial-ankle pulse wave velocity; BMI: body-mass index; CAC: coronary artery calcium; CAD: coronary artery disease; Cl: confidence interval; CT: computed tomography; GTP: gamma-glutamyltransferase; hsCRP: high-sensitivity C-reactive protein; HDL: high-density lipoprotein; LDL: low-density lipoprotein; MDCT: multidetector computed tomography; OR: odds ratio; PP: pulse pressure; PWV: pulse wave velocity.

\section{Authors' contributions}

KS takes full responsibility for the data collection and integrity of the analyses. JY contributed to the hypothesis, participated in its design and drafted the manuscript. SR participated in the design of the study and performed the statistical analysis. SL, BK $, \mathrm{BK}^{2}, \mathrm{JK}^{1}, \mathrm{EC}, \mathrm{JK}^{2}$, JP reviewed/edited the manuscript and contributed to discussion. KS is the guarantor for the article and all authors have read and agreed the manuscript as written. All authors read and approved the final manuscript.

\section{Author details}

${ }^{1}$ Division of Cardiology, Department of Medicine, Kangbuk Samsung Hospital, Sungkyunkwan University School of Medicine, \#108, Pyung Dong, Jongro-Ku, Seoul 110-746, Republic of Korea. ${ }^{2}$ Department of Occupational and Environmental Medicine, Sungkyunkwan University School of Medicine, Seoul, Republic of Korea. ${ }^{3}$ Department of Cardiology, Wonju College of Medicine, Yonsei University, Wonju, Republic of Korea. ${ }^{4}$ Department of Medicine/Cardiology, Cheil General Hospital, Dankook University College of Medicine, Seoul, Republic of Korea.

\section{Acknowledgements}

We acknowledge the efforts of the health screening group at Kangbuk Samsung Hospital, Korea.

\section{Competing interests}

The authors declare that they have no competing interests.

Received: 28 August 2015 Accepted: 28 October 2015

Published online: 04 November 2015

\section{References}

1. Greenland P, Bonow RO, Brundage BH, Budoff MJ, Eisenberg MJ, Grundy SM, et al. ACCF/AHA 2007 clinical expert consensus document on coronary artery calcium scoring by computed Tomography in global cardiovascular risk assessment and in evaluation of patients with chest pain: a Report of the American College of Cardiology Foundation Clinical Expert Consensus Task Force (ACCF/AHA Writing Committee to Update the 2000 Expert Consensus Document on Electron Beam Computed Tomography) developed in collaboration with the society of atherosclerosis imaging and prevention and the society of cardiovascular computed tomography. J Am Coll Cardiol. 2007;49(3):378-402.

2. Margolis JR, Chen JT, Kong Y, Peter RH, Behar VS, Kisslo JA. The diagnostic and prognostic significance of coronary artery calcification. A report of 800 cases. Radiology. 1980;137(3):609-16.

3. Budoff MJ, Shaw LJ, Liu ST, Weinstein SR, Mosler TP, Tseng PH, et al. Long-term prognosis associated with coronary calcification: observations from a registry of 25,253 patients. J Am Coll Cardiol. 2007:49(18):1860-70.

4. Raggi P, Gongora MC, Gopal A, Callister TQ, Budoff M, Shaw LJ. Coronary artery calcium to predict all-cause mortality in elderly men and women. J Am Coll Cardiol. 2008;52(1):17-23.

5. Raggi P, Shaw LJ, Berman DS, Callister TQ. Prognostic value of coronary artery calcium screening in subjects with and without diabetes. J Am Coll Cardiol. 2004;43(9):1663-9.

6. Shaw LJ, Giambrone AE, Blaha MJ, Knapper JT, Berman DS, Bellam N, et al. Long-Term prognosis after coronary artery calcification testing in asymptomatic patients a cohort study long-term prognosis after cac testing in asymptomatic patients. Ann Intern Med. 2015;163(1):14-21.

7. Rumberger JA. Tomographic plaque imaging with CT: technical considerations and capabilities. Prog Cardiovasc Dis. 2003;46(2):123-34.
8. O'Rourke RA, Brundage BH, Froelicher VF, Greenland P, Grundy SM, Hachamovitch R, et al. American College of Cardiology/American Heart Association Expert Consensus document on electron-beam computed tomography for the diagnosis and prognosis of coronary artery disease. Circulation. 2000;102(1):126-40.

9. Haberl R, Becker A, Leber A, Knez A, Becker C, Lang C, et al. Correlation of coronary calcification and angiographically documented stenoses in patients with suspected coronary artery disease: results of 1764 patients. J Am Coll Cardiol. 2001;37(2):451-7.

10. Budoff MJ, Young R, Lopez VA, Kronmal RA, Nasir K, Blumenthal RS, et al. Progression of coronary calcium and incident coronary heart disease events: MESA (Multi-Ethnic Study of Atherosclerosis). J Am Coll Cardiol. 2013;61(12):1231-9.

11. Budoff MJ, Hokanson JE, Nasir K, Shaw LJ, Kinney GL, Chow D, et al. Progression of coronary artery calcium predicts all-cause mortality. JACC Cardiovasc Imaging. 2010;3(12):1229-36.

12. Wong ND, Nelson JC, Granston T, Bertoni AG, Blumenthal RS, Carr JJ, et al. Metabolic syndrome, diabetes, and incidence and progression of coronary calcium: the Multiethnic Study of Atherosclerosis study. JACC Cardiovasc Imaging. 2012;5(4):358-66.

13. Vlachopoulos C, Aznaouridis K, Stefanadis C. Prediction of cardiovascula events and all-cause mortality with arterial stiffness: a systematic review and meta-analysis. J Am Coll Cardiol. 2010;55(13):1318-27.

14. Oberoi S, Schoepf UJ, Meyer M, Henzler T, Rowe GW, Costello P, et al. Progression of arterial stiffness and coronary atherosclerosis: Iongitudinal evaluation by cardiac CT. AJR Am J Roentgenol. 2013;200(4):798-804.

15. Sugawara J, Hayashi K, Yokoi T, Cortez-Cooper MY, DeVan AE, Anton MA, et al. Brachial-ankle pulse wave velocity: an index of central arterial stiffness? J Hum Hypertens. 2005;19(5):401-6.

16. Cainzos-Achirica M, Rampal S, Chang Y, Ryu S, Zhang Y, Zhao D, et al. Brachial-ankle pulse wave velocity is associated with coronary calcium in young and middle-aged asymptomatic adults: the Kangbuk Samsung Health Study. Atherosclerosis. 2015;241(2):350-6.

17. Liu CS, Li Cl, Shih CM, Lin WY, Lin CH, Lai SW, et al. Arterial stiffness measured as pulse wave velocity is highly correlated with coronary atherosclerosis in asymptomatic patients. J Atheroscler Thromb. 2011;18(8):652-8.

18. Seo WW, Chang HJ, Cho I, Yoon YY, Suh JW, Kim Kl, et al. The value of brachial-ankle pulse wave velocity as a predictor of coronary artery disease in high-risk patients. Korean Circ J. 2010;40(5):224-9.

19. Yamashina A, Tomiyama H, Takeda K, Tsuda H, Arai T, Hirose K, et al. Validity, reproducibility, and clinical significance of noninvasive brachial-ankle pulse wave velocity measurement. Hypertens Res. 2002;25(3):359-64.

20. Agatston AS, Janowitz WR, Hildner FJ, Zusmer NR, Viamonte M Jr, Detrano R. Quantification of coronary artery calcium using ultrafast computed tomography. J Am Coll Cardiol. 1990;15(4):827-32.

21. Sung KC, Lim YH, Park S, Kang SM, Park JB, Kim BJ, et al. Arterial stiffness, fatty liver and the presence of coronary artery calcium in a large population cohort. Cardiovasc Diabetol. 2013;12:162.

22. Park JS, Choi UJ, Lim HS, Choi BJ, Choi SY, Yoon MH, et al. The Relationship between coronary artery calcification as assessed by multi-detector computed tomography and arterial stiffness. Clin Exp Hypertens. 2011;33(8):501-5.

23. Kronmal RA, McClelland RL, Detrano R, Shea S, Lima JA, Cushman M, et al. Risk factors for the progression of coronary artery calcification in asymptomatic subjects: results from the Multi-Ethnic Study of Atherosclerosis (MESA). Circulation. 2007;115(21):2722-30.

24. DeFilippis AP, Kramer HJ, Katz R, Wong ND, Bertoni AG, Carr J, et al. Association between coronary artery calcification progression and microalbuminuria: the MESA study. JACC Cardiovasc Imaging. 2010;3(6):595-604.

25. Huynh K. Coronary artery disease: predicting the progression of coronary artery calcification. Nat Rev Cardiol. 2014;11(10):557.

26. Pandey AK, Blaha MJ, Sharma K, Rivera J, Budoff MJ, Blankstein R, et al. Family history of coronary heart disease and the incidence and progression of coronary artery calcification: multi-Ethnic Study of Atherosclerosis (MESA). Atherosclerosis. 2014;232(2):369-76.

27. Erbel R, Lehmann N, Churzidse S, Rauwolf M, Mahabadi AA, Mohlenkamp $S$, et al. Progression of coronary artery calcification seems to be inevitable, but predictable-results of the Heinz Nixdorf Recall (HNR) study. Eur Heart J. 2014;35(42):2960-71.

28. McEvoy JW, Blaha MJ, Defilippis AP, Budoff MJ, Nasir K, Blumenthal $\mathrm{RS}$, et al. Coronary artery calcium progression: an important clinical 
measurement? A review of published reports. J Am Coll Cardiol. 2010;56(20):1613-22.

29. Torii S, Arima H, Ohkubo T, Fujiyoshi A, Kadota A, Takashima N, et al. Association between pulse wave velocity and coronary artery calcification in Japanese men. J Atheroscler Thromb 2015. doi:10.5551/jat.30247.

30. Papanas N, Tziakas D, Maltezos E, Kekes A, Hatzinikolaou E, Parcharidis G, et al. Peripheral arterial occlusive disease as a predictor of the extent of coronary atherosclerosis in patients with coronary artery disease with and without diabetes mellitus. J Int Med Res. 2004;32(4):422-8.

31. Won KB, Chang HJ, Kim HC, Jeon K, Lee H, Shin S, et al. Differential impact of metabolic syndrome on subclinical atherosclerosis according to the presence of diabetes. Cardiovasc Diabetol. 2013;12:41.

32. Cox AJ, Hsu FC, Agarwal S, Freedman BI, Herrington DM, Carr JJ, et al. Prediction of mortality using a multi-bed vascular calcification score in the Diabetes Heart Study. Cardiovasc Diabetol. 2014;13:160.

33. Shemesh J, Tenenbaum A, Fisman EZ, Koren-Morag N, Grossman E. Coronary calcium in patients with and without diabetes: first manifestation of acute or chronic coronary events is characterized by different calcification patterns. Cardiovasc Diabetol. 2013;12:161.

34. Katakami N, Osonoi T, Takahara M, Saitou M, Matsuoka TA, Yamasaki Y, et al. Clinical utility of brachial-ankle pulse wave velocity in the prediction of cardiovascular events in diabetic patients. Cardiovasc Diabetol. 2014;13:128.

35. lino R, Yokoyama N, Konno K, Naito K, Isshiki T. Impact of combined assessment of coronary artery calcium score, carotid artery plaque score, and brachial-ankle pulse wave velocity for early coronary revascularization in patients with suspected coronary artery disease. Int Heart J. 2012;53(3):154-9.

36. Franklin SS, Wt Gustin, Wong ND, Larson MG, Weber MA, Kannel WB, et al. Hemodynamic patterns of age-related changes in blood pressure. The Framingham Heart Study. Circulation. 1997;96(1):308-15.

37. Messerli F, Ventura H, Glade L, Sundgaard-Riise K, Dunn F, Frohlich E. essential hypertension in the elderly: haemodynamics, intravascular volume, plasma renin activity and circulating catecholamine levels. Lancet. 1983;322(8357):983-6.

38. Min JK, Lin FY, Gidseg DS, Weinsaft JW, Berman DS, Shaw LJ, et al. Determinants of coronary calcium conversion among patients with a normal coronary calcium scan: what is the "warranty period" for remaining normal? J Am Coll Cardiol. 2010:55(11):1110-7.

39. Tsuchikura S, Shoji T, Kimoto E, Shinohara K, Hatsuda S, Koyama H, et al. Brachial-ankle pulse wave velocity as an index of central arterial stiffness. J Atheroscler Thromb. 2010;17(6):658-65.

\section{Submit your next manuscript to BioMed Central and take full advantage of:}

- Convenient online submission

- Thorough peer review

- No space constraints or color figure charges

- Immediate publication on acceptance

- Inclusion in PubMed, CAS, Scopus and Google Scholar

- Research which is freely available for redistribution

Submit your manuscript at

www.biomedcentral.com/submit

C Biomed Central 